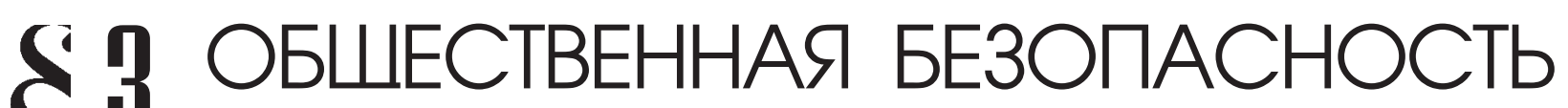

Н.С. Седых

\section{ТЕРРОРИЗМ В УСЛОВИЯХ ОБЩЕСТВА РИСКА: СОЦИАЛЬНО-ПСИХОЛОГИЧЕСКИЙ АНАЛИЗ}

\begin{abstract}
Аннотация: В статье анализируются социальные и психолого-политические предпосылки развития терроризма в условиях общества риска. В контексте глобальной информатизации соииального пространства и проблематики соииального конструирования рисков рассматриваются отдельные особенности средств массовой коммуникации, эксплуатация которых позволяет лидерам террористических организаций оказывать информаиионно - психологическое воздействие с иелью вовлечения молодых людей в террористическую деятельность. Обозначаются перспективы дальнейтего исследования в связи с необходимостью совершенствования методов профилактики терроризма в конкретных соииально-исторических условиях.
\end{abstract}

Ключевые слова: Соииология, терроризм, общество, риск, глобализация, воздействие, информация, коммуникаиия, представления, медиадискурс

$\mathrm{B}$ XXI веке терроризм стал неотъемлемой частью социального бытия и политической реальности. Известно, что с конца 1960 годов масштабы терроризма начали приобретать угрожающие размеры, а за период с 1986 г. по настоящее время число терактов увеличилось на 50-60\%. Одновременно с увеличением числа терактов изменяется их содержание и направленность: они становятся всё более жестокими и всё чаще угрожающими жизни людей. Так, в 1970-х годах 80\% терактов были направлены против собственности и только $20 \%$ против людей; в 1980-х годах - соответственно 50\% и $50 \%$; в 1990 -х годах соотношение составило уже $30 \%$ и $70 \%{ }^{1}$.

Однако следует особо подчеркнуть, что терроризм в его нынешних формах и проявлениях стал возможен в условиях развивающегося общества риска. Общество риска, полагает автор этого термина, немецкий социолог У. Бек, - это общество, чреватое катастрофами. Его нормальным состоянием может стать чрезвычайное положение. Автор, характеризуя особенности данного общества, указывал на состояние всеобъемлющего страха, все более овладевающее людьми. Соответственно, по мнению исследователя, риск может

${ }^{1}$ URL:http://www. Guardantiterror. ru быть определен как «систематическое взаимодействие общества с угрозами и опасностями, индуцируемыми и производимыми модернизацией как таковой» ${ }^{2}$. Это приводит к формированию качественно новых «социально опасных ситуаций» и интенсификации глобальных угроз, к числу которых относится и угроза терроризма. В то же время активное производство рисков, характерное для современного общества, влечёт за собой и изменение его социальной структуры - перестройки по критерию степени подверженности рискам. Это во многом определяется тем, что в современных условиях даже богатство и власть не могут гарантировать спасения индивида от глобальных катастроф. Вследствие отсутствия каких-либо гарантий физической, социальной, экономической безопасности нарастает социальная тревога. В результате, по мнению У. Бека, общество теперь объединяет не классовая солидарность, а солидарность страха. В силу названных причин происходит изменение общности и её цели ${ }^{3}$. Это, на наш взгляд, выражается, в частности, в том, что в настоящее время объединение участников террористических организаций происходит на осно-

\footnotetext{
${ }^{2}$ Бек У. Общество риска. На пути к другому модерну.- М.: Прогресс-Традиция, 2004.-с.131

${ }^{3}$ Там же
} 
ве религиозно-мировоззренческих установок. С точки зрения автора такая ситуация вполне соотносится с логикой развития современного общества, в котором объединение людей происходит по степени подверженности рискам. Причём солидарность такого рода и общие социальные страхи конкретной группы лиц нередко являются движущей силой развития идей относительно переустройства общества. Примером может служить активизация исламизма, являющегося идейным течением в мусульманской мысли новейшего времени, основанным на представлении о необходимости утверждения в обществе и государстве в определённых политических границах или в планетарном масштабе господства всеобъемлющего исламского комплекса правил поведения - шариата. Одновременно с этим в современных условиях также интенсивно развивается исламский экстремизм, который рассматривается как крайнее идейно-политическое течение в исламе, провозглашающее своей главной целью установление исламских форм государственной власти путем использования различных видов вооружённого и политического насилия. Однако ориентированная на создание «государства ислама» идеология исламизма отражает, в частности, стремление к сплочению мусульман в борьбе против экспансии европейского образа жизни и мыслей во имя сохранения ислама как религии и образцовой социальной модели. Исламисты критикуют негативные последствия модернизации, секуляризма и национализма для уммы как следствие засилья Запада ${ }^{4}$. В этой связи отметим, что, несмотря на глобальный и всеобъемлющий характер рисков, они распределяются неравномерно и становятся, прежде всего, уделом малоимущих. Анализируя данную проблематику, У. Бек указывает на очевидность того, что риски не упраздняют, а усиливают классовое общество и проблема распределения рисков становится главной по сравнению с проблемой распределения материальных благ.

Причём неравномерность распределения рисков, считает У. Бек, прослеживается и среди стран. Показательно, что рисков чаще и больше встречается в менее развитых странах ${ }^{5}$. Это привлекает внимание исследователей общества риска Э. Гидденса, У. Бека,

${ }^{4}$ Нечитайло Д.А. Современный радикальный экстремизм: стратегия и тактика/ отв. ред. В.Л. Шульц; Центр исследований проблем безопасности РАН.- М.: Наука, 2011.c.8, с.15

${ }_{5}^{5}$ Бек У. Что такое глобализация.-М.: Прогресс-традиция, 2001. - c. 330
Н. Лумана, которые связывают проблему распределения рисков с глобализационными процессами современности. В настоящее время признаётся, что глобализация отразилась на исламских странах преимущественно негативно. Несмотря на то, что страны с мусульманским населением изобилуют природными ресурсами, контраст между бедными и богатыми в них чрезвычайно велик и приближается к черте, за которой, по прогнозам аналитиков, возможен революционный взрыв. Вместе с тем, глобализация, проникая в исламский мир, обостряет внутренние противоречия: усиливает деградацию политических систем, деформацию моральных и семейных ценностей. В силу этого исламский мир в целом настроен против глобализации на западных основаниях. По мнению Э. Геллнера, именно ислам способен стать глобальной политической системой, предложить альтернативный вариант глобализации 6 .

Соответственно, создание объединенного исламского государства, что и объявляется стратегической целью террористов, позволит лоббировать собственные социально-политические интересы и отстаивать культурную самобытность. В этой связи следует отметить, что единовластный руководитель организации «Братья-мусульмане» аль -Худайби заявил: «У нас одна неизменная программа. Её цель - сплотить людей на почве истины, любви, братства, дружбы и сострадания, чтобы жить по законам шариата» ${ }^{7}$. Заметим, что сходным образом идею «государства ислама» прокомментировал и имам соборной мечети г. Ростова-на-Дону в ходе фокусированного интервью, проводимого нами в целях определения специфики социального восприятия терроризма с точки зрения представителей традиционного ислама. Он отметил: «Если обратиться к Корану, то высшая цель джихада - основать шариатское государство. Такое, которое живет по законам Аллаха, - проще говоря, идеальное. В нем люди должны жить в здравии, любви, дружбе, никто не должен в чем-либо нуждаться и тем более - кого-то ненавидеть». Однако он особо подчеркнул, что «наивысший джихад - это, когда человек говорит слово истины в лицо несправедливому правителю, то есть тирану». Вместе с тем он подчеркнул, что «джихад как вооружённая борьба направлен только против тех, кто агрессивен в отношении мусульман,

${ }^{6}$ Gellner E. Religion and the Profane // News Letter. 1997. JulyOctober. P. 25.

${ }^{7}$ Kramer M. The Islamic Debate. Tel Aviv, 1997. P.42 


\section{Политика и общество 4 (100) • 2013}

воюет с ними и вынуждает их защищаться (на что Аллах нам дал право, как и любому человеку в опасности)». В ходе нашей беседы имам с горечью заявил, что «любые священнослужители в России и мусульманское духовенство тоже ведут активную деятельность по борьбе с экстремизмом, в том числе и через интернет». Однако, к великому сожалению религиозных деятелей, «радикально настроенные мусульмане не посещают просветительские сайты и не ходят в мечети, где исповедуют традиционный ислам».

На наш взгляд, это в определённой степени обусловлено тем, что глобализация в интерпретации Э. Гидденса, является фактором отрыва индивидов, социальных групп, институтов от привязки к локальным социокультурным ситуациям. В условиях глобализации разрушаются социальные связи, которые в традиционных и индустриальных обществах выполняли функции формирования социального порядка. Вместе с тем они давали индивиду социальную стабильность, чувство надежности бытия, уверенности в будущем и защищенности.

В то же время такая ситуация сковывала личную инициативу, ограничивала свободу выбора, подчиняла личность группе. Разрушение этих связей освобождает индивида от традиционных ограничений и одновременно лишает его ощущения незыблемости основ бытия, надежды на социальные гарантии. Это повышает чувство тревожности и страха перед необходимостью выбирать. К тому же у индивида не остается возможностей положиться на традиции или переложить на кого-то (сообщество, лидера, специалиста) бремя риска. В силу этих причин, утверждает Э. Гидденс, глобализация порождает общество риска как состояние всеобщей озабоченности, неуверенности и страха ${ }^{8}$.

Как известно, одним из базовых источников терроризма является психологическое состояние общества или его психолого-политическая нестабильность. В сложившихся обстоятельствах обусловленная неизбежностью рисков социальная тревога, становится, с точки зрения У. Бека, новым фактором образования и поддержания общественного порядка, основанного на расширении сферы политического через делегирование ей проблемы интерпретации рисков. В то же время институционализированная система производства риска объединяет индивидуальный и коллективный риск. Индивидуальные жизненные возможности или уровень экономической безопасности сегодня

${ }^{8}$ Гидденс Э. Ускользающий мир. - М.: Весь мир, 2003. - с.89 связаны с опасностями, порождаемыми динамикой глобальной экономикия.

В контексте данной проблематики терроризм представляет собой сочетание высокого уровня политической мотивации с низким уровнем участия масс ${ }^{10}$. Причины этого заключаются в том, что объективные факторы, детерминирующие общественные процессы, находят своё социально-психологическое отражение в индивидуальном и групповом сознании в форме установок, стереотипов; а также доминирующих психологических состояний. Это и является непосредственным мотивационным регулятором поведения людей. Так, профессор Я. Росс из университета Балтимора, придерживается мнения, согласно которому психологический тип террориста - смертника формируется под воздействием социальных и психологических факторов. Социальные условия включают политический и экономический уровень развития общества, историко-культурные условия, степень недовольства и вектор направленности обид, эффективность контртеррористических мероприятий спецслужб. Я. Росс считает, что модернизация, демократия и социальные проблемы создают структурные условия для развития терроризма. Вместе с тем исследователь выделяет семь факторов, способствующих экстремизму: боязнь остаться невостребованным, сильное эго, депрессия, чувство вины, агрессия, кризис общества, рост числа тех, чья личность пострадала ${ }^{11}$.

Отметим, что представители антитеррористоческих ведомств констатируют: в настоящее время инициатива перешла к молодому поколению исламистов $^{12} .$. В этой связи подчеркнём, что молодежь, в силу своего особого положения, подвергается рискам в значительно большей степени, чем другие социальные группы. Причём наиболее ярко это проявляется в странах и регионах, где наблюдается социально-экономическая нестабильность. В такой ситуации возникают трудности при решении жизненно важных вопросов:

\footnotetext{
${ }^{9}$ Бек У. Что такое глобализация.-М.: Прогресс-традиция, 2001. - c.338

${ }^{10}$ Осипова A. A. Справочник психолога по работе в кризисных ситуациях / А. А. Осипова. - Изд. 2-е. - Ростов-на-Дону, Феникс, 2006, - с. 116

${ }^{11}$ Pedahzur A. Root Causes of Suicide Terorrism:The Globalization of Martyrdom. N. Y.: Routledge, 2006. P. 13-14

${ }^{12}$ Нечитайло Д.А. Современный радикальный экстремизм: стратегия и тактика/ отв. ред. В.Л. Шульц; Центр исследований проблем безопасности РАН. - М.:Наука, 2011.- с. 113
} 
получении образования, построении карьеры, создании семьи. Это затрудняет поиск путей конструктивной реализации духовного, интеллектуального, творческого потенциала и становится значимой предпосылкой развития агрессии и деструктивных форм социального поведения. Вместе с тем гигантский разрыв между имущими и неимущими людьми во многих странах и регионах мира может приводить к образованию и поддержке различных повстанческих и террористических групп. Люди, которые фактически не имеют материальных жизненных ресурсов (и, следовательно, почти ничего не теряют) становятся первыми кандидатами для вступления в экстремистские организации, обещающие лучшие условия жизни после того, как имущие будут лишены власти ${ }^{13}$.

В то же время известны случаи, когда террористами-смертниками становятся социально благополучные люди. Например, в журнале, издаваемым «АльКаидой», подробно описываются биографии шахидов и приводится интервью одного из смертников, который опровергает то, что молодые люди становятся смертниками в результате депрессии и бедности: «Я понимаю, что означает операция самопожертвования. Я студент из состоятельной семьи. У меня нет проблем с психикой и т.д. Я могу закончить обучение и стать врачом» ${ }^{14}$.

Такое деструктивное поведение, по нашему мнению, только на первый взгляд кажется не имеющим социальных причин и психологических предпосылок, однако они обнаруживаются при рассмотрении отдельных особенностей развития современного общества. Во-первых, классовое расслоение общества, сохраняя значимость на одних уровнях социальной организации, утрачивает смысл в отношении рисков. В данном контексте речь идет о единстве общества перед ними: «...модернизационные опасности раньше или позже приводят к единству преступника и жертвы» ${ }^{15}$. Важнейшим следствием наблюдаемого «эффекта бумеранга», по мнению У. Бека, является социальное и экономическое отчуждение, связанное с обесцени-

${ }^{13}$ Соснин В. А. Психология современного терроризма.- М. : ФОРУМ, 2010.- 160 с., с. 16

${ }^{14}$ См. Нечитайло Д.А. Современный радикальный экстремизм: стратегия и тактика/ отв. ред. В.Л. Шульц; Центр исследований проблем безопасности РАН.-М.:Наука, 2011.c. 112

${ }^{15}$ Бек У. Общество риска. На пути к другому модерну.- М.: Прогресс-Традиция, 2004.-с.245 ванием территорий, ресурсов, деятельности в связи с подверженностью модернизационным рискам. В результате этих процессов, по мнению исследователя, сегодня в любом обществе люди постоянно подвергаются определенным рискам. В благополучном, процветающем обществе могут доминировать одни риски, а в нестабильном, кризисном - другие. Избавиться от нарастающих угроз в условиях глобальности рискогенных факторов не удается никому ${ }^{16}$. В этой связи возможно усиление различных социальных страхов, которые могут иметь реальную основу, а могут быть преувеличены. Отметим, что чрезмерно преувеличенный страх - это страх, основанный на искажённом восприятии. Следовательно, он может приводить к ошибочному анализу реальных опасностей и неадекватным мерам противодействия. В частности, может иметь место такое экстремально-эмоциональное реагирование на потенциальный источник опасности, которое блокирует рациональный анализ информации. Это, в свою очередь, может запускать механизм формирования образа «коварного врага». Преувеличенный страх может также породить эскалацию насилия как ответную реакцию на угрозу ${ }^{17}$.

Во - вторых, риски имеют тенденцию к усилению, так как они продукт передовых современных технологий, к числу которых относятся и средства массовой коммуникации. Вследствие этого зачастую «неизведанные и неожиданные последствия приобретают характер господствующей силы» ${ }^{18}$.. Например, глобальная информатизация социального пространства повлекла за собой развитие движения всемирного джихада и интенсификацию террористических угроз. Причём по заявлениям идейных вдохновителей соответствующих организаций в современных условиях медиаджихад рассматривается как равный по своей значимости войне с оружием в руках и может составлять $90 \%$ от общих усилий экстремистов ${ }^{19}$. Столь сильная концентрация внимания на медиа-составляющей деятельности вполне объяснима тем, что вследствие активного развития информационной сферы, по мне-

\footnotetext{
16 Там же

${ }^{17}$ Соснин В. А. Психология современного терроризма.- М. : ФОРУМ, 2010. c. 39

${ }^{18}$ Бек У. Общество риска. На пути к другому модерну.- М.: Прогресс-Традиция, 2004.-с.318

${ }^{19}$ Нечитайло Д.А. Современный радикальный экстремизм: стратегия и тактика/ отв. ред. В.Л. Шульц; Центр исследований проблем безопасности РАН.-М.:Наука, 2011.- с. 77
} 


\section{Политика и общество 4 (100) • 2013}

нию М. Московичи, задача удержания власти предстаёт как коммуникативная задача. Сходного мнения придерживается и известный американский футуролог Э. Тоффлер, полагающий, что на современном этапе знание и информация стали важнейшими ресурсами власти. Это во многом обусловлено тем, что, по мнению многих исследователей, риски «объективно» существуют лишь в форме знаний о них и, исходя из этого, их целесообразно рассматривать как социально конструируемые феномены. Основной предпосылкой развития данной концепции служит следующее положение: «правда о риске» конструируется посредством общественного дискурса, стратегий, практик и институций. В фокусе внимания исследователей, опирающихся на работы М. Фуко, оказывает вопрос о том, каким образом различные концепции риска порождают специфические нормы поведения, которые могут быть использованы для мотивирования индивидов к свободному участию в процессах самоорганизации в ситуациях связанных с рисками ${ }^{20}$. В частности, Н. Луман предлагает постигать феномен риска соответственно смыслу коммуникаций ${ }^{21}$. В этой связи необходимо отметить, что коммуникативное действие, считает Ю. Хабермас, как символически опосредованная интеракция, во-первых, задаёт систему отсчёта для описания и понимания происходящего, для конструирования его как предмета познания, во-вторых, коммуникативное действие - это конкретно-исторический процесс производства социальной реальности ${ }^{22}$.. Следовательно, в контексте данной проблематики риск имеет знаково- символическое содержание и интерпретативное воплощение в сообщении о нём.

Вместе с тем усложнение и динамичность социальных процессов в обществе, влияние происходящих общественных изменений непосредственно на повседневную жизнь человека делают его все более зависимым от потока сообщений средств массовой коммуникации. Все меньше сведений, необходимых для своего социального поведения и жизни в обществе, он может получить, основываясь только на своем повседневном опыте. Все больше необходимой социальной информации

\footnotetext{
20 Яницкий О.Н. Социология риска: ключевые идеи. Электронный ресурс. Режим доступа: www.socio.ru/wr/1-03/ Yanizky.htm 12.12.2006.

${ }^{21}$ Луман Н. Рельность массмедиа.-М.: Праксис, 2005.- с.24

${ }^{22}$ Хабермас Ю. Моральное сознание и коммуникативное действие / Пер. с нем. под ред. Д. В. Скляднева, послесл. Б. В. Маркова. - СПб.: Наука, 2000. —c.57
}

современный человек получает из теле- и радиопрограмм, периодических изданий и Интернет - ресурсов. Особенно ярко это проявляется в формировании мнений по вопросам, которые не находят отражения в его непосредственном опыте, например, об обстановке в других городах, регионах, странах, о политических лидерах, об экономической конъюнктуре, международном терроризме и т.п. Вследствие этого усиливается влияние массовой коммуникации на повседневную жизнь человека. Масс-медиа создают для него своего рода «второю реальность», «субъективную реальность», которая оказывает значительное, а при определённых условиях, приоритетное воздействие на социальное мышление и поведение личности ${ }^{23}$.

В связи с этим «не зная действия средств коммуникаций, невозможно понять общественные и культурные изменения... Средства коммуникаций, изменяя среду, вызывают в нас необычные соотношения чувственных восприятий. Расширение любого чувства изменяет образ нашего мышления и деятельности нашего восприятия мира. Когда изменяются эти соотношения, изменяются и люди...», - утверждает М. Маклюэн ${ }^{24}$. Это преимущественно определяется тем, что деятельность масс-медиа происходит в определённом смысловом пространстве. СМК не представляет (или повторно представляет) фрагмент реальности, а скорее производят или конструируют его 25 . При этом сконструированные медиа образы, порождают реальные эмоциональные и когнитивные реакции и побуждают к определённым социальным действиям. Это иллюстрирует и комментарий имама соборной мечети г. Ростова-на-Дону, относительно того, что побуждает молодых людей участвовать в террористической деятельности: «Средний возраст таких людей, к примеру, уроженцев Дагестана, - уже от 14 до 22 лет. В этом тоже ответ на вопрос «что ими движет». Отсутствие опыта и чужая воля. Это очень молодые, юные ребята. В основном они искренне верующие, но были введены в заблуждение - например, насмотрелись на сомнительных сайтах разнообразных обращений Саида Бурятского, Доку Умарова и прочих и попали под их

\footnotetext{
${ }^{23}$ Богомолова Н.Н. Социальная психология печати, радио и телевидения. - М.: МГУ, 1991.- 57

${ }^{24}$ Маклюэн Г.М. Понимание Медиа: Внешние расширения человека. М., 2003.- С. 26.

${ }^{25}$ Fiske J. Television and Postmodernism. In: Curran J., Gurevitch M. (eds.) Mass Media and Society. L.: Edward Arnold, 1991. PP. 55-67
} 
влияние». Отметим, что именно такие сюжеты способны оказывать значительное информационно - психологическое воздействие, так как одна из неспецифических функций СМК - функция присвоения статуса общественным проблемам, организациям, движениям и конкретным личностям. Внимание средств массовой коммуникации свидетельствует, что объект сообщения достоин быть выделенным из анонимной массы, его поведение и мнения достаточно важны для всех ${ }^{26}$. Это эксплуатируется лидерами террористических организаций. Показательным примером служит также следующий случай. В мае 2007 г. ведущий известного радикального форума по прозвищу «Моджахед 1988» обратился к многочисленным посетителям со словами: «Прощайте, Я люблю вас всех. Молитесь все за меня, чтобы я стал шахидом». Через некоторое время на форуме были размещены подробности гибели «Моджахеда 1988». Безусловно, обращение популярного ведущего одного из форумов находит отклик в молодёжной среде и обладает пропагандистским эффектом ${ }^{27}$.

Вместе с тем, целенаправленное управление информационными потоками, позволяет «достичь искомых целей, минимально расходуя ресурсы власти; убедить людей в их личной заинтересованности в этих целях; превратить противников в союзников» ${ }^{28}$. Очевидно, что это определяет активное использование Интернета террористами как средства коммуникации, пропаганды, вербовки. Так, в интересах всемирного джихада действует около 5600 сайтов, причём каждый год открывается около 900 новых ${ }^{29}$. Такая активность, безусловно, имеет определённые цели, продиктованные тем, что «информационная бомба взрывается в самой гуще людей, осыпая как шрапнелью образов и в корне меняя и восприятие нашего внутреннего мира, и наше поведение» ${ }^{30}$. В этой связи важно отметить, что в рамках исследовательской парадигмы социально-

${ }^{26}$ Назаров М.М. Массовая коммуникация в современном мире: методология анализа и практика исследований. М.: Прогресс, 2002. с.12

${ }^{27}$ Нечитайло Д.А. Современный радикальный экстремизм: стратегия и тактика/ отв. ред. В.Л. Шульц; Центр исследований проблем безопасности РАН.-М.:Наука, 2011.- с. 114

${ }^{28}$ Тоффлер Э. Метаморфозы власти. -М.: АСТ, 2004. - с. 321

${ }^{29}$ Pool J. New Forum Postings Caal for Intensified ElecktronicJihad against Covernment Websites. 2005. Vol. 3/ Issue 8. 29 August 2012

${ }^{30}$ Тоффлер Э. Метаморфозы власти. -М.: АСТ, 2004. - с. 328 го конструкционизма, язык получает конститутивный статус, способность активно воздействовать на поведение и мышление людей и рассматривается как порождающий процесс. При этом под текстом понимается и устное выступление, и письменные материалы, и визуальные изображения, и даже значения, закодированные в одежде и манере ее носить. Фактически все, что так или иначе семантически нагружено, является проявлением того или иного дискурса и может быть определено как «текст» ${ }^{31}$

В силу этого Интернет позволяет осуществлять то, что Д. Деннинг назвала «управление восприятием - то есть террористы могут позиционировать себя точно такими, какими хотят казаться, без фильтров, налагаемых традиционными СМИ» ${ }^{32}$. В этой связи рассмотрим некоторые особенности конструирования экстремистских сайтов. Прежде всего, на подобных сайтах нечасто встречаются прямые призывы к насилию. Они выстроены преимущественно по модели сайтов легитимных политических движений и партий, поэтому основное внимание уделено описанию дела, за которое борются террористы. Вместе с тем большая часть наполнения сайтов террористических организаций состоит из справочных материалов, в первую очередь, по истории движения. Заметим, что именно недостаточность освещения идеологического контекста экстремистской деятельности отличает медийные репрезентации терроризма в традиционных СМИ. С помощью Интернета террористы пытаются компенсировать данный недостаток ${ }^{33}$.

Это позволяет сделать и размещение видеообращений боевиков, которые зачастую подробно раскрывают политическую и социальную мотивацию экстремистской деятельности и позиционируют себя как борцов за справедливое мироустройство. Сходные цели имеет и созданная по инициативе бен Ладена компания «асСахаб», производящая профессиональные видеоклипы, продвигающая «культуру джихада» ${ }^{34}$.

${ }^{31}$ Фуко, М. Археология знания : пер. с фр. / М. Фуко ; общ. ред. Бр. Левченко. - К. : Ника-Центр, 1996. - с. 201

32 Denning D.E. Assessing the computer network operations threat of foregn countries // Information strategy and warfare. Ed. by J. Arquilla, D.A. Borer. — New York - London, 2007. - P.31

${ }^{33}$ Tsafti Y., Weimann G. www.terrorism.com: Terror on the Internet // Studies in Conflict \& Terrorism. 2002. Vol. 25.P. 317-332.

${ }^{34}$ Нечитайло Д.А. Современный радикальный экстремизм: стратегия и тактика/ отв. ред. В.Л. Шульц; Центр исследований проблем безопасности РАН.-М.:Наука, 2011.- с. 114 


\section{Политика и общество 4 (100) • 2013}

Однако террористы постоянно совершенствуют способы информационно-психологического воздействия. Например, Хезболла даже выпустила компьютерную игру, которую Центральный Интернет-отдел разрабатывал два года ${ }^{35}$. Необходимо отметить, что компьютерная реальность рассматривается сегодня как тип виртуальной и обозначается как опыт новой эпохи, обнаруживший способность к изменчивости без предела, лабильность, интуитивность и иррационализм самой человеческой природы. Активный пользователь Интернета ощущает его пространство как пространство без границ. В этом виртуальном мире всё возможно: начать всё сначала или создать будущее «...Шанс «жизни наоборот» обуславливается отсутствием точек невозврата ... персонажи легко взаимозаменяемы. Они обладают сверхчеловеческими возможностями...» 36 Личность воспринимает себя создателем мира, имеющего статус онтологического. А все метаморфозы, случающиеся в нём с персонажем и временем, не отличаются от живых, то есть не являются вторичными. Однако многие из этих людей теряют способность к различию реальных артефактов и виртуальных, компьютерных и подлинных. Иными словами, они готовы воплощать в реальность агрессивные модели поведения, освоенные с помощью компьютерной игры. Это во многом обусловлено тем, что виртуальный образ, несмотря на то, что он является продуктом психической реальности, кажется более живым, истинным, обладает собственной активностью и может оказывать регулирующее воздействие на поведение человека. В этой связи следует отметить, что функция опосредованного поведения является важнейшей функцией социальных представлений, которые обеспечивают разделяемые коды социального взаимодействия и позволяют конвенциализировать объекты, идеи, теории, события и отношения, подчиняя их обыденности, здравому смыслу. Исследователь данного феномена М. Московичи, указывает на то, что представления основаны не на тех вещах и ситуациях, которые в них упоминаются, а на коммуникации, касающейся этих вещей и ситуаций ${ }^{37}$.

${ }^{35}$ Hoffman B. Inside Terrorism / Rev. and expanded ed. N.Y.: Columbia University Press, 2006. P. 225

${ }^{36}$ См. Ярёменко С. Н. Неоконченные дискурсы жизненных смыслов.- Ростов-н-Д: Изд-во «Эверест», 2007.- с.66

${ }^{37}$ Московичи С. Социальные представления. Исторический взгляд // Психологический журнал. - 1995. - Т. 16. - № 1-2. - c. $11-22$
Исходя из вышеизложенного можно сделать вывод, что учет рассмотренных особенностей современного общества и его информационной сферы позволяет лидерам террористических движений использовать различные пропагандистские и манипулятивные способы, чтобы развивать медиадискурс о терроризме таким образом, который способствует формированию соответствующих социальных представлений, позволяющих рассматривать террор как конструктивный способ социально-политических преобразований и личностной самореализации. Мы считаем необходимым дальнейший всесторонний теоретико-эмпирический анализ современного терроризма, который, с точки зрения автора, является способом информационно-психологического воздействия с целью управления социумом посредством превентивного устрашения и достижения социально-политических и экономических целей ${ }^{38}$. Результаты данного исследования, на наш взгляд, будут полезны при оптимизации системы информационно-психологического противодействия терроризму и повышении эффективности мероприятий психолого-педагогического характера, направленных на профилактику развития идей экстремизма и терроризма среди подростков и молодёжи.

\section{Библиография:}

1. Бек У. Что такое глобализация.-М.: Прогресс-традиция, 2001.- с.330

2. Бек У. Общество риска. На пути к другому модерну.- М.: Прогресс-Традиция, 2004.-с.131

3. Гидденс Э. Ускользающий мир.-М.: Весь мир, 2003.- c.89

4. Емельянова Т.П. Социальное представление: понятие и концепция: итоги последнего десятилетия // Универсальные базы данных изданий России и стран СНГ. URL: http://www.ebiblioteka.ru/ sources/article.jsp?id=3684782, 2002.

5. Луман Н. Рельность массмедиа.-М.: Праксис, 2005.- c. 24

6. Маклюэн Г.М. Понимание Медиа: Внешние расширения человека. М., 2003. - С. 26.

${ }^{38} \mathrm{Cedblx} \mathrm{H.} \mathrm{C.} \mathrm{Современный} \mathrm{терроризм} \mathrm{с} \mathrm{точки} \mathrm{зрения} \mathrm{ин-}$ формационно-психологических угроз. - Национальная безопасность. -№ 2 (19) . - 2012 -. с.70 
Общественная безопасность

7. Московичи С. Социальные представления. Исторический взгляд // Психологический журнал. 1995. - Т. 16. № 1 2.- c.11-22

8. Назаров М.М. Массовая коммуникация в современном мире: методология анализа и практика исследований. М.: Прогресс, 2002. с.12

9. Нечитайло Д.А. Современный радикальный экстремизм: стратегия и тактика/ отв. ред. В.Л. Шульц; Центр исследований проблем безопасности РАН.- М.: Наука, 2011. -431 с.

10. Соснин В. А. Психология современного терроризма.- М. : ФОРУМ, 2010. с. 16

11. Тоффлер Э. Метаморфозы власти. - М.: АСТ, 2004. - c. 321

12. Хабермас Ю. Моральное сознание и коммуникативное действие / Пер. с нем. под ред. Д. В. Скляднева, послесл. Б. В. Маркова. - СПб.: Наука, 2000. с.57

13. Ярёменко С. Н. Неоконченные дискурсы жизненных смыслов.- Ростов-н-Д: Изд-во «Эверест», 2007.- c.66

14. Hoffman B. Inside Terrorism / Rev. and expanded ed. N.Y.: Columbia University Press, 2006. P. 225.

\section{References (transliteration):}

1. Bek U. Chto takoe globalizatsiya.-M.: Progress-traditsiya, 2001.- s.330

2. Bek U. Obshchestvo riska. Na puti k drugomu modernu.- M.: Progress-Traditsiya, 2004.-s.131

3. Giddens E. Uskol'zayushchiy mir.-M.: Ves' mir, 2003.-s.89
4. Emel'yanova T.P. Sotsial'noe predstavlenie: ponyatie i kontseptsiya: itogi poslednego desyatiletiya // Universal'nye bazy dannykh izdaniy Rossii i stran SNG. URL: http://www.ebiblioteka.ru/sources/article.jsp?id=3684782, 2002.

5. Luman N. Rel'nost' massmedia.-M.: Praksis, 2005.s. 24

6. Maklyuen G.M. Ponimanie Media: Vneshnie rasshireniya cheloveka. M., 2003. - S. 26.

7. Moskovichi S. Sotsial'nye predstavleniya. Istoricheskiy vzglyad // Psikhologicheskiy zhurnal. 1995. - T. 16. № 1 2.- - s.11-22

8. Nazarov M.M. Massovaya kommunikatsiya v sovremennom mire: metodologiya analiza i praktika issledovaniy. M.: Progress, 2002. s.12

9. Nechitaylo D.A. Sovremennyy radikal'nyy ekstremizm: strategiya i taktika/ otv. red. V.L. Shul'ts; Tsentr issledovaniy problem bezopasnosti RAN.M.: Nauka, 2011. -431 s.

10. Sosnin V. A. Psikhologiya sovremennogo terrorizma.-M. : FORUM, 2010. s. 16

11. Toffler E. Metamorfozy vlasti. -M.: AST, 2004. s. 321

12. Khabermas Yu. Moral'noe soznanie i kommunikativnoe deystvie / Per. s nem. pod red. D. V. Sklyadneva, poslesl. B. V. Markova. - SPb.: Nauka, 2000. s.57

13. Yaremenko S. N. Neokonchennye diskursy zhiznennykh smyslov.- Rostov-n-D: Izd-vo «Everest», 2007.-s.66

14. Hoffman B. Inside Terrorism / Rev. and expanded ed. N.Y.: Columbia University Press, 2006. P. 225. 